\title{
'It's normal to have damp': Using a qualitative psychological approach to analyse the lived experience of energy vulnerability among young adult households
}

Danielle Butler and Graeme Sherriff

Authors' affiliation: Sustainable Housing \& Urban Studies Unit, School of Nursing, Midwifery, Social Work and Social Science, University of Salford, Salford, UK.

Corresponding Author: Danielle Butler, Sustainable Housing \& Urban Studies Unit, School of Nursing, Midwifery, Social Work and Social Science, University of Salford, Allerton Building, University of Salford, Salford, M6 6PU. Email: $\underline{\text { d.e.butler@edu.salford.ac.uk }}$

ABSTRACT

Seeking to promote methodological innovation in fuel poverty research, this paper reflects on the use of a novel qualitative psychological approach known as Interpretative Phenomenological Analysis. The benefits and limitations of this methodological approach are discussed within a detailed account of the findings from a small-scale study undertaken in Salford, UK. Contributing to an existing gap in the existing evidence base, the research focused on the lived experience of young adult households: a demographic group identified as being disproportionately more likely to be living in fuel poverty compared to any other age group. Three emergent themes were identified: 'establishing the independent home', 'threats to home comfort' and 'energy and coping'. Multiple references to conditions typical of fuel poverty disclosed, such as: self-disconnection, energy debts, cold homes and unrelenting challenges with damp and laundry practices. 'Vulnerability' mostly consumed narratives of past experience, with participants discussing the present and future with positive affectivity. 
Implications for further research are explored, including the potential to more effectively target support by reframing current discourse away from one centred on 'vulnerability'.

Keywords: Fuel poverty, young adult households, Interpretative Phenomenological Analysis, energy vulnerability, making home, threats to comfort, coping.

\section{INTRODUCTION}

Fuel poverty is estimated to affect 2.38 million, or as many as one in ten households in England. ${ }^{1}$ Young adult households - those where the oldest member is younger than twenty-five - are disproportionately more likely to be fuel poor compared to any other age group. ${ }^{1}$ Despite this, relatively little attention in fuel poverty research has been directed specifically towards this demographic group.

Contributing to this gap in the literature, this paper will present and discuss the findings from a small-scale qualitative study undertaken in Salford, UK. The main aim of the research was to identify and analyse how young adults construct and make sense of their understanding of domestic energy in the independent home, as well as considering the ways in which they may perceive themselves to be burdened or threatened by energyrelated challenges or vulnerabilities. Seeking to promote methodological innovation in fuel poverty research, one of the main aims of this special edition, this paper will also provide a detailed discussion and reflection on the use of a qualitative psychological approach, known as Interpretative Phenomenological Analysis. 


\section{FUEL POVERTY}

What is fuel poverty?

Fuel poverty has been described as "a recognised social problem that affects the poor, with its roots in the quality of the housing stock and the cost of fuel". 2. Essentially, it is the convergence of three factors - low-income, energy inefficient housing and high energy costs - that is understood to shape the extent of fuel poverty. Boardman ${ }^{2}$ notes the importance of the built environment, arguing that low-incomes and high costs are experienced by nonfuel poor households and that the inefficient home is the distinguishing characteristic with some of the poorest people having to buy 'expensive warmth'. Other research has highlighted the importance of taking into account factors such as skills, knowledge and social relations in the context of the dynamics of managing a home ${ }^{3}$, as well as the ways in which issues such as poor mental health limit the capacity of people to get the best out of their home heating. ${ }^{4}$ Fuel poverty can therefore be understood as a multifaceted experience that is shaped by costs, income, housing, and personal and social circumstances.

Traditionally, fuel poverty has been understood to relate to the capacity of a household to afford to adequately heat the home at a reasonable cost. Nevertheless, and although more than half of the residential energy supply is used for space heating ${ }^{5}$, fuel poverty can also be thought of more broadly as: "a condition in which a household lacks a socially- and materially-necessitated level of energy services in the home". ${ }^{6}$ This conceptualisation implicates the wide and varied range of wider energy uses in the home such as cooking, cleaning, entertainment, and socialising.

The negative impacts of fuel poverty on physical and mental health and wellbeing have been well documented. Physical health impacts include respiratory, cardiovascular, 
circulatory conditions and excess winter deaths. ${ }^{7}$ Liddell and Guiney ${ }^{8}$ found associations between cold and damp homes and 'sub-optimal mental wellbeing', citing stressors such as low income, fear of debt, damage to possessions from mould and damp, and social isolation. Research has also examined indirect impacts of fuel poverty beyond health, illustrating negative consequences in relation to social isolation, educational performance, emotional well-being, resilience, dietary opportunities and choices, as well as dexterity and the risk of accidents and injuries in the home. ${ }^{7}$

Fuel poverty and young adult households The decision to research fuel poverty among young adult households was motivated by a number of factors. Firstly, government statistics show that in relation to householder age there are disproportionate levels of fuel poverty among households where the oldest member is younger than twenty-five (24.3\%). ${ }^{1}$ Worryingly, this does not represent a new phenomenon: an increased prevalence of fuel poverty among this age group, compared to all other age groups, has been observed consistently over the last decade. ${ }^{1}$

Secondly, low income and poor housing - two of the significant drivers of fuel poverty generally tends to have a substantial impact upon households of younger adults. For instance, for those aged 16-24, median income (after housing costs) stands at only half that of the national average, and substantially lower than that of any other age category. ${ }^{9}$ For those who are seeking paid employment, a weekly payment of jobseeker's allowance is $20 \%$ less than that paid to those over the age of $25 .{ }^{10}$ It is also within this age period that individuals tend to embark upon their first experiences of independent household management. Research has identified that young adults tend to live in some of the poorest 
housing, typically situated within the private rented sector. ${ }^{11}$ Fuel poverty, therefore, is just one part of a complex set of challenges faced by this age group.

Thirdly, and forming the main motivation for this research, young adult households remain a significantly under-researched group within the broader fuel poverty literature. A review of the wider evidence base revealed only one study to date. ${ }^{12}$ Conducted by Bouzarovski and colleagues, the research concentrated on a densely populated urban area in England, aiming to "explore the extent to which such individuals suffer from fuel poverty as a result of moving out of the parental home, while identifying some of the main housing and social features of households in this group". ${ }^{12}$ Employing a mixed methods approach, 320 surveys were completed, as well as thirty-six in-depth interviews with flat-sharing young adults, a majority of whom were students (68\% of surveyed households).

Young adult households were regarded as being at an increased risk of fuel poverty due to a number of factors, such as: the energy inefficiency of properties typically rented by this age group (i.e. those within the private rented sector), exploitation by and poor relationships with landlords, bundling of rent and utility costs, and a lack of awareness regarding energy efficiency or fuel poverty assistance.

The authors concluded that among households of this age there might be a failure to recognise or acknowledge conditions indicative of fuel poverty. Firstly, this could be due to a lack of awareness among young people regarding energy efficient behaviours, and the energy efficiency of the home, a finding that has been well documented in the literature ${ }^{13-}$ ${ }^{14}$. Secondly, a failure to recognise conditions indicative of fuel poverty may be influenced by a "widespread cultural expectation that it is acceptable for individuals to live in poorly heated and low quality housing at the entry point of their housing career". ${ }^{12, \text { p.8 }}$ Thirdly, as 
tenants within the private rented sector, participants conveyed limited capacity to act regarding their situations, a finding that has been further supported elsewhere..$^{3,11,15 .}$

Critically, these findings illustrate key challenges for strategies that set out to alleviate or eradicate fuel poverty. The potential to effectively target support towards this demographic group is restricted partly by issues related to a lack of recognition. Essentially, if young adult households do not conceive of themselves as living in or at risk of fuel poverty, the likelihood of them actively seeking out or acknowledging assistance directed towards them will be low.

\section{Approaches to researching fuel poverty}

As with any social issue, there are a range of approaches to researching fuel poverty, each with its own advantages and limitations. Recent commentary, however, has argued that the present body of work has drawn too heavily on statistical representations of the issue (i.e. the fuel poverty gap), demonstrating a tendency to draw upon definitions only in terms of macro-level indicators. ${ }^{15}$ Valuable insights gained from a growing body of qualitative research ${ }^{3,15-17}$ have much to offer in response.

There are many recognised advantages in taking a qualitative approach within the context of fuel poverty research. Qualitative approaches allow for in-depth explorations of experiences and social relationships, taking account of feelings, opinions and perspectives. They enable an understanding of causality: explaining why trends and relationships occur in data, and understanding behaviour. Through flexible techniques such as semi-structured interviewing, they create openness and include scope for unexpected findings that can open up new areas of research. However, as we will discuss in the subsequent sections of this paper, qualitative approaches are not without challenges and limitations. 


\section{METHODOLOGY}

Interpretive Phenomenological Analysis

The qualitative research approach chosen for this study was Interpretative Phenomenological Analysis (IPA) - a prominent method that operates within the epistemological framework of phenomenology. ${ }^{18} \mathrm{~A}$ phenomenological approach was deemed suitable as, fundamentally, it seeks to generate a greater understanding of human lived experience. ${ }^{19}$ Introducing the theoretical foundations of IPA, Smith, Flowers and Larkin $^{20}$ note that:

"IPA is an approach to qualitative, experiential and psychological research which has been informed by key concepts and debates from three key areas of the philosophy of knowledge: phenomenology, hermeneutics and ideography"

From this perspective, IPA research expresses a concern with how individuals, for whom certain experiences are shared, construct personal meaning and make sense of their lived experience within particular contexts. ${ }^{20}$ IPA can be characterised in three ways: as ideographic, inductive, and interrogative.$^{21}$ It is said to follow an ideographic approach in that analysis focuses on the particular, aiming to "arrive at a rich description of individual cases" ${ }^{22}$ It is considered to be inductive in that it uses broad research questions to arrive at expansive data and to allow unanticipated aspects of experience the freedom to emerge. Lastly, IPA research is regarded as interrogative in that at its centre is a psychological focus where the researcher aims to 'interrogate' or 'illustrate' existing evidence in a given research area.

IPA takes a central position between experiential and discursive approaches. ${ }^{22}$ Through phenomenology, it expresses philosophical concern with experience, and the meaning such 
experiences hold for individuals. ${ }^{20}$ Fulfilling the discursive approach, language is explored and perceived as a social action used to construct an individual's social world..$^{23}$ Through their accounts, participants are attempting to make sense of their experiences described as an 'interpretative endeavour'.$^{20}$ For the researcher, a critical realist approach is taken where "a cautious view between what is said...and a participant's actual experience" is needed. ${ }^{22}$ For the present research, IPA was found to be particularly beneficial in that it provided an approach where interviewees' experiences could be shared and made sense of through interaction. In this relatively nascent area of fuel poverty research, it was felt to be important to let individuals express their experiences as they perceived them and to minimise the extent to which the researchers own views and experiences could frame the analysis. In doing so, this adds to a growing body of work that advocates 'bottom up' approaches to researching fuel poverty and energy vulnerability. ${ }^{15}$

Design and sample

The research consisted of six in-depth semi-structured interviews. Participants were recruited through a branch of the UK advice organisation Citizens Advice, based in Salford, Greater Manchester. The sampling criteria set out to include young adults, aged 18-24 years-old, who had recent or current experience of independently managing the home (and therefore recent or current experience as energy consumers). Adopting a proxy based approach to identify young adult households living in or at risk of fuel poverty, the sample was further restricted to include only those who, at the time of living independently, also had experience of being unemployed, not in education or training and/or of claiming a means-tested benefit. 
The sample consisted of five female participants and one male. Participants resided in either social housing or the private rented sector, and the amount of time spent living independently ranged from three months to more than five years. Household composition varied considerably: three participants lived as a member of a couple without children, one lived with a partner and their two children, one as a lone parent, and the sixth participant lived alone.

Interviews were guided by a set of prompts, focusing initially on broader experiences of independent household management before moving towards a more specific consideration of the interviewees' experiences as energy consumers. Interviewees were asked about their transitions to living independently; the practical, structural and social dynamics of managing the independent home; financial aspects (i.e. income and essential household costs) of living independently; and their experiences related to domestic energy services, uses and billing practices.

Delivering the research: Reflecting on the practical aspects of the study Before reporting on the findings of the research, we will use the following sections to reflect on some of the key methodological considerations and challenges encountered during the fieldwork.

Identifying 'vulnerable' or 'at risk' households

Traditionally, fuel poverty has been measured using the $10 \%$ indicator by which a household is considered to be fuel poor if needing to spend " 10 percent of income on energy to maintain a healthy living environment". ${ }^{24}$ Following the Hills' review in 2012, a revised definition and measure was introduced - the Low income high Cost Indicator (LIHC) - which uses median levels of income and energy costs to determine which households are classified 
as fuel poor. ${ }^{25}$ This measure has since been implemented within the revised 2015 Fuel Poverty Strategy for England (other devolved nations within the UK - Wales, Scotland and Northern Ireland - continue to use the $10 \%$ measure $)^{26}$, and used to determine the scale of the problem as reported in the two most recent Annual Fuel Poverty Statistics Reports. ${ }^{1,26}$ In fuel poverty research, however, relatively few studies use either measure when determining the sample under study. ${ }^{27}$ Indeed, it can be time-consuming and intrusive to gain accurate measures of a household's income, costs or information related to the performance or characteristics of the property, and people are unlikely to self-report as fuel poor. Instead, more commonly found within the literature is a focus on certain 'at risk' groups (i.e. older households or those with a disability), or the application of proxy based approaches to 'identify' the fuel poor (for example, low income households).

For the present study, the sampling strategy combined a focus on a specific 'at risk' group (households where the oldest member is younger than twenty-five) with the adoption of a proxy indicator (low-income). This combined approach was used to identify low-income, young adult households, who could arguably be regarded as having an even greater likelihood to be living in fuel poverty. This approach, however, is recognised as problematic in that it cannot be known for sure whether or not participants would be classified as 'fuel poor' under formalised definitions (i.e. the $10 \%$ measure or the LIHC indicator).

Furthermore, in recognising the importance of considering the changing nature of people's circumstances, the concept of energy vulnerability became central to the research. ${ }^{12,15}$ This concept explores the experiences of fuel poverty not as a fixed state - where a household either is or isn't fuel poor - but instead considers how different households may have 
varying degrees of vulnerability in terms of their exposure, sensitivity and adaptive capacity. ${ }^{15}$

Situating the researcher

As with many phenomenological research methods, "IPA accepts the impossibility of gaining direct access to the research participants' life worlds" ${ }^{18}$, therefore, as noted, participants are considered to be attempting to make sense of their experiences through reflective processes termed the 'interpretative endeavour' ${ }^{20}$ Central to this process is also the role of the researcher who is "trying to make sense of the participant trying to make sense of what is happening to them". ${ }^{20}$ Referred to as a double hermeneutic, this requires the researcher themselves to engage in the 'interpretative endeavour', whereby attempts are made to understand such experiences from the participants' perspective. ${ }^{23}$ Consequently, as Willig ${ }^{18}$ highlights, this necessarily implicates the role of the researcher, their own world views, assumptions and biases, as well the nature of the interviewer-interviewee interaction. Sullivan, Gibson and Riley ${ }^{22}$ posit that the "best way to deal with subjectivity is to give it an overt role in the research process". This forms a critical part of IPA research, where the researcher carefully engages in ongoing reflexive practices.

Reflexivity is deemed particularly critical at moments where key research decisions are made such as choosing the areas or phenomena to study, the development of research questions and design, through to the generation, analysis and interpretation of data, as well as throughout the production of the final written account. Use of a research diary was vital in this process, particularly during the period in which the interviews were completed. Combining reflective notes with the interviews transcripts helped to ensure that the analysis 
was grounded firmly in the participants' accounts, as well as providing a supplementary source of data.

Other considerations relate to the first author's personal and professional experience. As a young adult renter living within the private rented sector, the process of engaging in reflexivity allowed such personal experiences to be positioned in a way that could enhance and enrich interpretations inferred from the participants' narratives. In terms of professional experience, and of key relevance to the present study, was the acknowledgement of the first author's role as a formally trained advisor for Citizens Advice. As an insider, the researcher is: "in a unique position to study a particular issue in depth and with special knowledge about that issue. Not only do you have your own insider knowledge, but you have easy access to people and information that can further enhance that knowledge". ${ }^{28}$ It was critical, however, to reflect upon and take steps to manage the two separate professional identities (i.e. as a researcher and an advisor). For instance, this was especially important during face-to-face interviews, which were completed in the same space in which the role as an employee would be undertaken. Attempting to distinguish between the two roles, sufficient time was allowed between the interviews being completed and days when working as an advisor. In addition, interviews were only completed during hours when the organisation was closed to the public, helping to envision the space as somewhere distinct and separate.

Engaging with people on issues of a sensitive nature Qualitative research exploring complex social issues related to various forms of deprivation and poverty asks people to talk about issues of a sensitive nature. For the present study, this focused on young adults' experiences of living independently on a low income, while 
exploring in greater detail energy-related challenges and vulnerabilities, such as cold, damp or poor quality housing.

Engaging with people on issues of a sensitive nature begins with participant recruitment, particularly when recruiting demographic groups considered to be 'vulnerable' or 'at risk'. Taking place in a local branch of Salford Citizens Advice, recruitment posters were displayed in the general waiting area and in each of the private consultancy rooms. Raising an important ethical consideration, the decision to display posters in private spaces was considered an important element of participant recruitment, giving those individuals who may wish to participate in the research but did not want to show an interest publicly, the opportunity to do so. Ritchie et al. ${ }^{29}$ note that this is particularly important in public spaces where often the reason for attending, separate to the research, "may itself be a source of anxiety".

The value of the professional expertise gained at Citizens Advice was beneficial in this regard, within which high importance was also placed on ethical context and being able to deal with sensitive issues. An advisor is required to conduct an interview, though motivated by a different set of aims, with a view to gathering key information and proposing possible actions and solutions. The researcher, on the other hand, places greater emphasis on seeking to establish a sense of understanding and meaning from what they are being told. For the present study, it was critical for the purpose of the interview to be made completely clear to the participant from the outset, in an effort to appropriately manage expectations. Where ongoing or new issues were introduced by participants, for example in relation to energy supply or poor housing conditions, individuals were reminded that further support could be accessed from the organisation. In dealing with sensitive issues as they arose 
during the interviews, processes of 'active listening' were applied to identify moments of distress or unease. Participants were reminded throughout their involvement in the research that they could ask questions about the nature and purpose of the study. They were also made aware that they had full control over their contribution and were under no obligation to talk about difficult or upsetting issues. Ultimately, the most important measure in dealing with sensitive topics and ensuring participant control over the interview relied on an emphasis of the participants' right to withdraw from the research at any stage, without needing to give a reason and without consequence.

Sample size

Qualitative data most often takes the form of transcribed dialogue between the researcher and the participant(s). Such methods are time-intensive for the researcher and yield large quantities of data ${ }^{22}$; therefore, a critical methodological consideration concerns the point at which 'enough' data has been generated.

Extensive scholarly discussion surrounds what defines the 'optimal' sample size ${ }^{30-32}$. One view is that this is determined once 'data saturation' has been achieved ${ }^{33,34}$; whereby the researcher continues to conduct interviews until they are able to identify clear patterns across the participants' experiences. ${ }^{35}$ For IPA research, the principal concern is to ensure that there is a full and detailed appreciation of each individual's account, or 'case' as it is often referenced within the literature; therefore, sample sizes are generally small. ${ }^{36}$ 'Optimal' sample size in IPA depends on a range of factors: (1) the depth of analysis of a single case, (2) the richness of each individual case, (3) the extent to which the researcher wants to compare or contrast single cases, and (4) practical restrictions when undertaking the research. IPA researchers have indicated that anywhere between three and eight 
participants is appropriate for research undertaken as part of a postgraduate research degree (as was the case for the present study). ${ }^{20,36}$

\section{ANALYSIS AND FINDINGS}

Analytic procedure

The analytic approach drew from the guiding principles of IPA as outlined by Smith, Flowers and Larkin ${ }^{20}$ and was completed in three main stages. Interview transcripts were approached individually at first, engaging in detailed and repeated readings. Transcripts were supplemented with the field notes, as well as extracts taken from the research diary. Sullivan et al. ${ }^{22}$ note that, in IPA, initial readings allow the researcher to gain "a holistic sense of the breadth and depth of the experiences the participant has talked about". Adhering to the ideographic approach adopted in IPA, attempts were made to bracket emergent ideas and themes from each of the individual transcripts. Although a certain level of influence from previous cases is recognised by the IPA researcher as inevitable ${ }^{20}$, attempts to overcome this were made by allowing sufficient time, where possible, between the analysis of each transcript.

Subsequent readings involved a close line-by-line analysis of the text and it is at this stage that we closely attended to the participants' experiential claims, perceptions, concerns and understandings. ${ }^{20,37}$ Transcripts were annotated with particular focus given to content, use of language, context and interpretative comments. ${ }^{23}$ Following this, the analytic focus turned from the transcripts towards the broad set of notes, which were brought together to begin to identify emerging themes. It is at this stage, as Smith et al. ${ }^{20}$ note, that "the original whole of the interview becomes a set of parts" following a process of re-organisation and 
fragmentation. Themes with conceptual similarity were clustered, and assigned descriptive labels.

The next stage of the analysis set out to integrate the emergent themes developed from each of the individual cases. Extracts to support each of the emergent themes were taken from the interview transcripts, and this was brought together to identify patterns across the data set as a whole. From this, themes of theoretical or conceptual similarity were clustered and, adhering to the iterative nature of qualitative research, were reviewed multiple times. In some cases, themes were relabelled and redefined. Once final master themes had been established, excerpts from the transcripts were selected to capture the essence of the themes, patterns and interpretations from the data.

The table below (Table 1 ) introduces the three master themes, as well as a number of corresponding sub-themes. The following sections will present a discussion of the main findings, including excerpts from the interviews. All interviewees have been assigned a pseudonym.

Table 1. Master themes

\begin{tabular}{|c|c|c|}
\hline Theme One & Theme Two & Theme Three \\
\hline $\begin{array}{l}\text { 'Making Home': Establishing the } \\
\text { independent home }\end{array}$ & $\begin{array}{l}\text { Energy Vulnerability and } \\
\text { Threats to Home Comfort }\end{array}$ & Energy and Coping \\
\hline 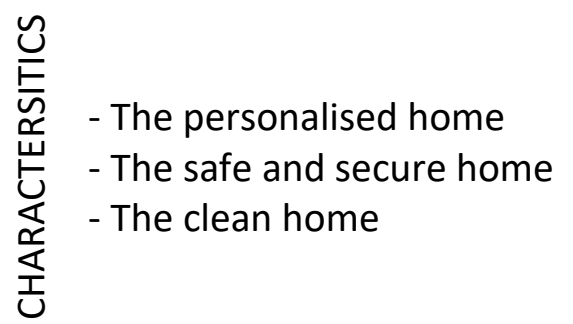 & 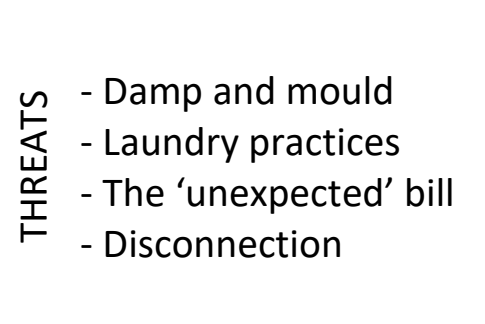 & $\begin{array}{l}\text { - Behavioural } \\
\text { - Psychological }\end{array}$ \\
\hline
\end{tabular}


Findings

Each of the following sections build upon the previous, guiding the reader through the analysis. First, the varied and dynamic housing pathways of the sample are discussed, illustrating a similar sense of transience and precariousness as evidenced in earlier research. ${ }^{12}$ Next, in introducing the first master theme, the analytic focus adopts a broader lens to consider the lived experience of establishing the independent home and specifically, introduces three characteristics identified by the interviewees as critical to this process. Essentially, the experience of 'making home' is narrated as one closely linked to the young adults' understandings and perceptions of home comfort. Focusing more specifically on energy-related experiences, and in presenting the second master theme, four energyrelated threats to home comfort are presented. The third and final master theme takes a step further to discuss behavioural and psychological mechanisms of coping with such threats.

Housing pathways

As highlighted by Bouzarovski and colleagues, the housing pathways of young adults can often be characterised as transient and precarious, with the authors concluding that as a result this demographic group may represent a "part of society that is invisible to fuel poverty assistance". ${ }^{12}$ In view of this, the present study was intentionally broadened to consider not only specific energy-related experiences, but also the lived experience of young adults moving into and managing the independent home.

The sample had varied and dynamic housing pathways, providing detailed insights into the historical, social and cultural backgrounds of the participants. Despite the small sample size, the interviewees revealed a broad array of life experiences, with no two participants 
following the same trajectory. Participants discussed three housing phases represented by the 'parental home', 'temporary homes' (such as university accommodation, hostels provided as part of homelessness provision or a short-term return to the parental home), and the 'independent home'. There was considerable diversity in the participants' 'parental homes' which were set across various tenures, as well as across a wide-ranging geographical context, spanning various parts of the UK, one European country (Poland), and across an international setting (Iran, Sudan and Israel). The age at which participants left the 'parental home' ranged from eighteen to twenty-one years-old.

Transitions between phases were not presented in a linear way and most participants revealed multiple experiences of moving back and forth between 'homes' as a result of, among other reasons: property condition, starting or finishing university, unemployment, homelessness, changes to household income, becoming a parent, and overcrowding. Participants clearly distinguished between the three phases when communicating their experiences, and this was particularly evident in discussions surrounding their roles and responsibilities as independent household members, including those related to energy provision and coping with energy-related challenges or vulnerabilities.

In their 'independent homes', participants were situated across the social housing and private rented sectors. None of the interviewees had past or current experience of home ownership; therefore, such experiences were entirely narrated from their perspectives as tenants. This implicated the role of others such as social housing providers, private landlords and estate agents, introducing various issues related to power and agency in the home, which will be noted on further throughout the following sections.

Making Home: Establishing the independent home 
As Hopkins ${ }^{38}$ notes: "a very important aspect of young people's lives is often the experience of 'making home' and the practices and processes associated with this". In taking an initial broader approach to the analysis, the first master theme considers this perspective in detail, presenting three characteristics of 'making home'. Generally, interviewees constructed their interpretations of independence and adulthood largely as a set of expectations and responsibilities. Central to this was their capacity to provide and sustain adequate resources to ensure home comfort. Although limited, this did at times refer to their ability to ensure adequate warmth in the home, as well as broader provision of energy services.

"We made it our own": The personalised home

Almost all of the participants suggested that the capacity to make changes to the living space - more specifically to personalise it or 'make it your own' - was of critical importance. Personalisation included tasks such as decorating, displaying pictures or artwork, purchasing furniture or making small adaptations to the living space (i.e. making changes to the kitchen or garden), and was presented by all of the interviewees with a sense of pride and achievement. The task was, however depicted as a substantial challenge, requiring monetary, physical and emotional investment, as well as the freedom or capacity to make the desired, and to some degree necessary, changes to a space that is only rented and not owned.

In their position as tenants, the interviewees frequently evidenced a sense of housing insecurity, discussing the negative implications this could have for any invested efforts to personalise the independent home. For one of the interviewees, Rehana, a twenty-threeyear-old mother of two, considerable steps had been taken to personalise and consequently improve the standard of her rented home; however, the family were promptly and 
unexpectedly left with no alternative but to move following the landlord's decision to sell the property.

Because we fitted a new kitchen, we made it our own. We decorated how we liked. It was lovely at the end of it and we had just started decorating more, we had started doing all the glossing and then we had to move out. The garden was fine for us, and it was, it was just home, really. My little big bubble. (Rehana)

Describing the previous home as "my little big bubble", Rehana's dialogue makes use of an interesting metaphor. Presented as a bubble, the home is perceived as a cosy, amniotic environment for herself and her family; however, as with the unpredictability of a bubble, which could pop at any time, her attachment to the space is similarly capricious.

The interviewees also presented challenges related to a heightened awareness of living in 'shared spaces' in which the "capacity to exercise individuality and autonomy" 39 , in terms of personalising the living space, had to be reconciled with that of the other residents: "you can't put your pictures up on the wall because it's your picture and it's not your housemate's

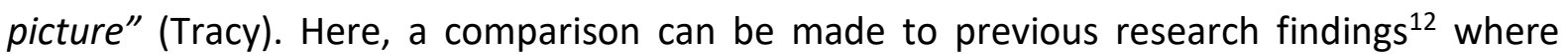
processes of reconciliation and renegotiation among young adults have been noted in relation to the energy needs and affordability of household members in shared living arrangements. Tensions would be avoided, with interviewees from earlier research suggesting that they “would allow themselves to get cold because they don't want to cause an argument with those on tighter budgets who can't afford any more heating". ${ }^{12}$ This demonstrates the extent to which this awareness can shape many aspects of a young adult's lived experience, from efforts to personalise the independent home to achieving adequate thermal comfort, adding 
support to a recognised need for more research which examines certain household formations such as houses in multiple occupation. ${ }^{40,41}$

The safe and secure home

A recurrent theme in the interviews was a sense among participants that the home should be symbolic of a protective space; a responsibility that the participants perceived to be their own. Narratives commonly combined notions of security and comfort, suggesting that, from the interviewees' perspective, one was dependent upon the other. For some participants, the importance of safety and security at home was emphasised through their identities as parents or caregivers. The analysis questioned if such interpretations, to some extent, may be gendered, with previous research highlighting that interpretations of home among female household members are often depicted more so as a place of "refuge or site of protection". ${ }^{38}$

Narratives focusing on safety and security also revealed interpretative contrasts between temporary and permanent homes, with the former being perceived as a space unable to offer this. Interviewees described perceived threats while living in 'temporary arrangements' not only to their personal safety and security but also regarding the potential for loss or damage of personal possessions. Strategies to mitigate potential loss or damage were employed, such as storing objects of attachment in a place that could be considered "protected and safe" (Jo). Echoing the views of other interviewees, Jo outlined that the 'parental home' was a place which could be relied upon in this regard:

For me it is a lot about my possessions as well. I like to feel like all of my things are protected and safe in the home and when I was in that place I didn't feel like that at 
all. I didn't want to have any of my stuff there. I left a lot of it with my parents unless I needed it because I didn't feel like, it didn't feel like a home. It felt temporary. (Jo)

The clean home

The third process of establishing the independent home centred on domesticity. Interviewees talked at length about their responsibilities in this regard, focusing on common tasks such as cleaning, cooking and laundry. Domestic duties were portrayed as household behaviours to be learned by young adults when entering the independent home, and interviewees disclosed how the transition from the 'parental home' involved a realisation of the scale of the domestic burden when living independently. Constructing their position in this way, as a 'novice' independent household member, indicated that such perceptions may also impact upon energy-specific lived experience in the independent home.

An interesting link between domesticity and energy vulnerability was revealed. At times, an inability to achieve an adequate level of warmth in the home was described as having a negative impact on their ability to carry out domestic duties to the standard required. One interviewee, Janet, observed a positive shift in her attitude and motivation towards domestic duties after moving into a new, warmer property:

Janet: I mean, I've been happier and I've been like...I wasn't as lazy as I was in the other house, like in the other house. In the new house I have more energy to clean and everything. And in the old one I didn't.

Interviewer: That's interesting, that relationship between not feeling comfortable and not being able to get things done... 
Janet: Yeh, it's easier for me to like, to go and clean the house. It takes me like an hour to do the whole house and when I was in the old house I just couldn't. It was hard to go from one room to another because it was...it was cold.

This excerpt highlights a critical connection between feeling cold and the ability to "get things done". Considering the concept of energy vulnerability ${ }^{15}$, Janet presents a clear example of 'sensitivity' to conditions indicative of fuel poverty. Here, the energy efficiency of the home, or a lack thereof, is suggested to have a direct relationship with the efficiency of the 'independent household member'. For Janet, living in a more energy efficient and consequently warmer home had resulted in more desirable and efficient domestic behaviours: "I have more energy" and "it takes me like an hour to do the whole house".

Energy vulnerability and threats to home comfort

Although 'comfort' was situated as a priority in establishing the independent home, references to thermal comfort - the ability to provide and sustain adequate warmth - were infrequent, suggesting that this did not necessarily represent a priority issue. In fact, the way in which the interviewees used and paid for domestic energy appeared to be characterised by a much more dynamic and complex relationship than one solely concerned with warmth. The second master theme explored this in detail, and is presented here under four sub-themes which correspond with a number of identified energy-related challenges or 'threats'.

Damp and mould

Interviewees discussed at length their experiences of poor household conditions, many of which were indicative of fuel poverty. Overwhelmingly, however, such discussions were focused on one household malady in particular: a widespread exposure to damp and mould. 
Interviewees discussed the negative impacts of the prevailing and seemingly unavoidable issue, which was positioned as the cause of considerable distress and a constant source of frustration. The form and severity of damp and mould varied: for some the issue was isolated to a single room, most frequently a bedroom or the bathroom, while for others more substantial areas of the property were affected. Some described the issue as an excessive build-up of condensation on the walls and around windows, while others outlined visible black marks and a resulting smell.

Only one of the interviewees, Rehana, outlined concerns regarding the negative consequences that damp and mould can have on physical health. This was presented in relation to an existing health condition, where, as an asthmatic, Rehana recognised a link between living with a damp or mould and periods of respiratory ill-health:

Well I'm asthmatic you see, so having damp in the room where you are, it causes your asthma to set off, plus you get more colds and coughs and what not, so it's the chest infections really, that the damp causes. (Rehana)

This awareness also extended outside of Rehana's family home, where she went on to discuss the serious health consequences of damp and mould for her mother, who had been diagnosed with Chronic Obstructive Pulmonary Disease (COPD):

It's a lung condition, and her bathroom and the bedroom are full of it and all they keep saying is it is condensation. Open the windows. Whereas my Mum has the windows open all the time to let the fresh air in because obviously she has got COPD, so they won't do anything about that. And it's been like that now for about two and half years, maybe longer. And it's literally black, all of the ceiling. So, yeh she has painted it, she 
has used damp proof paint, everything, it's just they won't do anything to help. (Rehana)

Both asthma and COPD are fluctuating chronic respiratory health conditions and, although not discussed in the interview, it is likely that both Rehana and her mother will have been provided with or have actively have sought out information and advice related to the management of their health conditions. In particular, this may have included information linked to environmental factors (e.g. damp and mould). Indeed, Rehana demonstrated with confidence her awareness of potential causes and ameliorative strategies; however, largely, efforts to date have failed to resolve the issue. Notably, Rehana demonstrates that a relationship between indoor moisture and damp is recognised and understood, evidencing 'good' household behaviours: "my Mum has the windows open all of the time". However, for her, the enduring exposure to damp and mould is attributed to the housing provider's failure to fully investigate.

Discussions focused on damp and mould exposed a major issue experienced by most of the interviewees. The relationships between tenants and those who owned or managed the properties (i.e. landlords and estate agents) were presented as problematic; a finding which has been similarly noted in the wider literature. ${ }^{11,12,15,17}$ Tenant-landlord relations were portrayed as strained and disjointed, resulting from a perceived lack of sincere or constructive communication, mostly evident in the interviewees' attempts to resolve issues related to damp and mould.

Yeh, we've got mould on the insides of our windows in every single room. It's because our vent is blocked up. And the agency just says it's old, because of the flat...it doesn't look that old though. And they said to us when we phoned up about it in the first winter 
we were here, um, to...that was that year when we had no money, I suppose...they said to keep the heating on low all the time. That's how you get rid of the mould. (Tracy)

As Tracy, highlights here, proposed 'solutions' from those who owned or managed the properties, such as "keep the heating on low all the time", were seen as unrealistic and unhelpful due to a lack of financial resources. For Rehana, the issue was deemed to be so severe that the family perceived no alternative but to move out of the property, resulting in a move from social housing into the private rented sector where the prevalence of fuel poverty tends to be greater:

I had my daughter in Sept and then we moved out three months later into [new property], because the damp was that bad in my bedroom. It was behind the wardrobe in my bedroom, my clothes were getting mouldy because the damp was penetrating through the wardrobe, form the back of the wardrobe. It was that bad. We told the council, they did nothing. So, we moved out. (Rehana)

Laundry practices

As noted, one of the major characteristics of 'making home' surrounded the young adults' ability to maintain adequate levels of cleanliness and evidence their efficiency regarding domesticity. The interviewees' narratives were dominated by one household task in particular: the process of 'doing laundry', or more specifically the practice of drying clothes.

All participants had current or past experience of living independently in a flat, without a garden, and therefore without access to an outdoor space to dry their laundry. Such practices were viewed as undesirable, unsightly and a nuisance within the living space. Furthermore, the interviewees frequently noted that this resulted in incongruent uses of the heating system, not as a means of staying warm, but as a way of doing the laundry. 
Laundry practices were also revealed to be a source of tension in the home, where interviewees revealed that other household members would attempt to justify their use of the heating system for reasons deemed to be 'acceptable', such as using it to dry clothes or in efforts to keep children in the home healthy and warm: "He would put it on full and like it was like a sauna in the house all of the time, and he would blame it on the kids or the laundry" (Janet). This further supports earlier research where particular energy practices, such as use of the heating system, have been found to carry of a risk of stigmatisation ${ }^{42}$, with individuals demonstrating an awareness of social approval or disapproval for a range of energy uses. It also emphasises the view that an individual's relationship with energy is situated within wider social and cultural understandings - an aspect of fuel poverty research to which qualitative methodologies are greatly suited.

Relating to the previous threat, participants also demonstrated an awareness of the link between drying laundry indoors and the high incidence of damp and mould: "...like the student house used to stink of damp and that was because I had my clothes everywhere" (Tracy). However, for many of the participants, the issue was particularly problematic due to a perceived absence of any alternative option for doing laundry:

“...What I'm looking forward to...having a washing line so I suppose you don't have to put the heating on because you are drying your clothes outside. Like, we had the heating on the other day and it's warm! It's not like...cold. But we had to do it" (Tracy)

One aspect which was evident across the participants' narratives concerning both damp and mould and laundry practices, was characterised by an unpleasant 'smell' brought about by drying laundry indoors. 
One thing I really didn't like was because it was damp there was a smell of damp so it would get onto all of your clothes and things. You couldn't really smell it because you lived in it but I was really self-conscious at first thinking 'oh everyone can smell, can probably smell that my clothes are really damp' (Jo)

All but one of the interviewees remarked on the issue and discussed the negative impact this had on their daily lives. As illustrated in the above excerpt, one of the predominant ways in which the participants discussed 'the smell' related to the risk of it being apparent to others when out in public (lingering on washed clothes), or when welcoming visitors into the home. In this regard, 'the smell' could be interpreted as not only a threat to the householder's home comfort, but also as a threat to their identity as a capable and independent young adult.

For Janet, the introduction of a tumble dryer had completely resolved the issue; however, in reinforcing the idea of 'acceptable' uses of energy services, it was stressed that the new appliance was reserved for use only when drying her children's clothes. Janet also unveiled a critical role played by parents in supporting some of the young adult interviewees with energy-related decision-making processes, even after they had left the parental home. Her decision to purchase a tumble dryer was positioned as one imposed upon her, stating that her mother convinced her to.

Janet: Now I have got a dryer. Because of my mum. Because my mum hated it when she was coming to my house and there was clothes hanging all over the house and she convinced me to get one [laughs].

Interviewer: Are you noticing benefits? 
Janet: Oh, it's so much better, it's like miles better. And the clothes don't stink. Because they, sometimes clothes don't dry quickly enough, they get 'the smell'.

However, the description of the purchase as a success story highlights that advice from trusted contacts, such as parents, remains invaluable. Janet's perspective was not uncommon, with many of the participants positioning their parents as trusted advisors and as key actors within their support network.

Interestingly, the interviews revealed that laundry practices were not perceived as a threat in terms of cost implications, for instance, due to increased energy costs as a result of operating a washing machine or tumble dryer. Instead, the participants revealed that the challenges were more commonly linked to the negative impacts this had on their private living space, as well as imposing a threat to their sense of self as an independent household member. This is not to say, however, that energy costs, bills, and household finances more broadly did not represent significant challenges for the interviewees, as the following discussion of the third threat to comfort - the 'unexpected bill' - will illustrate.

The 'unexpected bill'

Money represented another dominant theme across the participants' narrative accounts. It was portrayed as a constant strain and source of worry; a finding not wholly unexpected due to the sampling criteria adopted. All of the participants voiced past experiences of financial hardship, which for many were linked to periods of unstable income and unemployment. Instability of household income, one of the six key challenges to energy vulnerability proposed by Middlemiss and Gillard ${ }^{15}$, played a critical role in the participants' attitudes towards managing household finances overall. However, while a number of issues regarding the instability of household income were highlighted, the participants' concerns 
were significantly more focused on the instability of household outgoings. At the centre of these concerns were domestic energy bills and food costs, evidencing experience of the common 'heat or eat' dilemma.

Comparisons made with other household expenditure, such as rent and council tax, highlighted that domestic energy bills were the most problematic due to their variability and unpredictability. Perceived as a household cost which they were unable to predict, or prepare for, this manifested as a fear of the 'unexpected bill'.

Five of the six participants had experience of paying for their gas and electricity through a pre-payment meter (PPM), a method of payment which offered a sense of reassurance and the ability to maintain greater control of household costs. As Tracy described:

I feel like I'm in control of it when I'm using the PPM because I've paid that much. They are not going to scam me off, and l've paid 110 on my meter. I am not in debt. I am not like...so when your money runs out you put enough on to cover the emergency and what you need. So a direct debit, or a bill coming through the post and it might be, it might be 1200 , or it might be four hundred and something, I don't know what it's going to be. And that scares me because I am not sure. (Tracy)

The use of a PPM was also portrayed as a strategy for avoiding energy debts, where credit meters could result in households being "scammed off" (Tracy) by their energy supplier. For one interviewee, Janet, poor communication and a breakdown in the consumer-supplier relationship had resulted in her cancelling her monthly payments and consequently accruing substantial arrears on her gas and electricity accounts. What was striking in this case is that the affordability of energy, because of rising energy costs or a reduction in household income, was not positioned as the cause of the debt. In the UK, there are approximately 1.5 
million electricity and 1.4 million gas accounts in debt ${ }^{43}$. Janet's experience raises key questions regarding the circumstances that lead to households accruing fuel debts, which is perhaps not solely one of 'affordability', as well as the ensuing experiences of managing accounts that have fallen into arrears. This reflects the poor relationship many consumers perceive themselves to have with energy suppliers, and central to this, as demonstrated here, is often a lack of trust. ${ }^{44}$ It is necessary, therefore, to explore 'consumer vulnerability' from multiple angles, recognising the issue as one that is complex and multidimensional, and where numerous factors, such as the "policies, practices and behaviour of market players, and the way that the energy market operates" ${ }^{44, ~ p .4}$, can be seen to drive vulnerability

Another cause for concern regarding energy bills stemmed from early independent housing experiences under tenancy agreements that incorporate the contractual term of 'all bills included'. A fairly typical system found in student accommodation in particular, 'all bills included' generally involves the householder making regular fixed payments directly to the landlord which then covers a range of essential household costs, such as rent, fuel bills, and internet costs, among others. However, in the UK's current housing climate where 'flatsharing' or renting a room in a house in multiple occupation is considered, for many, the only affordable option, an increasing number of non-student, young adult renters are now also living under such tenancy agreements. For one interviewee, Tracy, this arrangement, in place for the first three years of living independently, had resulted in a lack of preparedness prior to receiving her first energy bill. 
And then moving into my house and getting a gas bill with your name on it is a really weird experience. Shit, have I actually got to pay this? And it's like I'm responsible for this, oh my god, where do I find the money for this? (Tracy)

This illustrates a major challenge faced by young adults renting under such tenancy agreements, where the visibility of energy use and costing in the home remains hidden for substantial periods early on in their housing careers. It highlights that there are clear opportunities to better prepare young adult households in terms of their relationship with and understanding of domestic energy in the independent home. A point of contact for clear information about energy charges and billing practices, for instance, would be particularly beneficial.

\section{Disconnection}

The fourth 'threat to comfort' centred on a fear of being disconnected. While none of the participants reported enforced disconnection from their energy supplier, some discussed multiple instances of self-disconnection, largely due to periods without sufficient financial resources. Unstable employment, delays in benefit payments, and unexpected household outgoings were the most common reasons for being unable to afford adequate gas and electricity.

Seemingly rejecting a sense of vulnerability, the impermanence of self-disconnection was stressed, with interviewees explaining that such periods were endured for only a short period of time, sometimes only a matter of hours. Arguably, this could be interpreted as a mechanism for managing one's self-concept, demonstrating greater levels of resilience. Research in psychology has highlighted that in developing "a positive self-concept, individuals may be well set up to maintain competence (i.e. demonstrate a resilient 
outcome) under a range of seemingly different kinds of adversities" ${ }^{45}$ In this case, the discursive switch from vulnerability to resilience evidences a possible strategy employed by young adult households to cope with energy-related challenges.

Motivations for avoiding instances of self-disconnection revealed an interesting concern among many of the participants: their narrative accounts suggested that the greatest fear of disconnection from energy services could be more accurately characterised by a fear of disconnection in a social sense. In particular, electricity was viewed as essential, not necessarily for heating or lighting but due to the additional energy services it provides. For all of the interviewees this concerned two services in particular: charging a mobile phone and access to the internet. As, Tracy, stated:

You can't do anything. You can't charge your phone. Which most people see as a priority, is having a mobile phone which it is, because how do you contact people if you don't have internet, if you don't have a phone. So...paying for your electricity has got to be the top one. Putting $£ 10$ on the meter and then knowing that there's $£ 5$ emergency if you need it. (Tracy)

Energy and coping

The third master theme referred to various strategies employed by the interviewees as a way of coping with energy-related challenges and vulnerabilities, many of which were discussed in relation to the identified threats to home comfort discussed in the previous sections. Coping strategies were generally presented in two ways: as behavioural or psychological strategies.

Behavioural mechanisms of coping 
Previous research has identified various strategies employed by households coping with cold homes, with the most common including a reduction in fuel use, going without other necessities, and incurring debt. ${ }^{46}$ The young adult interviewees in the present research similarly noted on some of these strategies, as well as others. Most mechanisms of coping were framed in terms of various day-to-day decision-making processes related to management of the independent home.

Firstly, although the interviews revealed limited discussion surrounding thermal comfort or adequate, affordable warmth, the interviewees did discuss mechanisms for coping with cold homes. The most common of these strategies focused on the living room, and specifically the sofa, as a site of warmth and comfort, often enhanced further by using blankets or sharing the space with other householders. The use of blankets to endure colder conditions in the home, outside typical hours spent in bed, is not a unique finding to this research. ${ }^{47}$ Research has even suggested that the use of a blanket, as a means of staying warm, may be interpreted by individuals as a positive experience: "the thought of slipping under their favourite blanket is a pleasant idea". ${ }^{47}$ This sentiment was echoed by some of the young adult interviewees in this research, and expanding upon this, it was noted how what had once been considered a coping strategy (the use of a blanket when cold during the day), had since become a habit, with the behaviour also adopted during times when not cold.

Another mechanism of coping discussed at length centred on 'fragile financial management ${ }^{\prime 47}$, where limited financial resources had to be balanced between various needs of the interviewees and other household members. In terms of domestic energy provision, for some of the interviewees, particularly those who were parents, energy needs were positioned as non-negotiable, resulting in compromise over other household 
essentials, such as the amount of money which could be spent on food. As illustrated by these findings and in previous research ${ }^{48}$, experiences of compromise and sacrifice in this context require complex decision-making processes and, at times, cause considerable psychological concern.

Thirdly, efforts to 'avoid the unexpected' were not discussed only in relation to energy bills: interviewees revealed other ways in which they attempted to evade negative energyrelated experiences. One strategy involved using proactive approaches to avoid issues related to damp and mould when viewing prospective properties. Interviewees regarded those responsible for letting properties, primarily estate agents, as dishonest and untrustworthy in this regard, outlining sophisticated strategies, such as searching inside cupboards and looking behind furniture, as a way of identifying if damp or mould was present. Notably, as Rehana highlights in the excerpt below, viewing properties in warmer, summer months made this task more challenging:

Yeh, I'm looking inside kitchen cupboards to see how the back of the cupboards are. Erm, I am looking for damp and I'm actually smelling for damp as well. But in the summer it is hard to detect damp anyway because it's...it clears out in the summer don't it, so in the winter it is easier to smell it. Looking at the roof, more than anything, that's one...they're, they're key facts that I look for in a house. The roof, to see if it's all been done, the gutters, to see if they have been done and all that because I don't want to move into a house and then oh god there's been a leak in the ceiling, or the gutters need doing and its causing damp in my bedroom, or...because that can all cause damp and that's one thing I don't need. (Rehana)

Psychological mechanisms of coping 
Predominately, interviewees demonstrated psychological mechanisms of coping in two ways. This involved: (1) positioning poor or undesirable experiences as impermanent and (2) evidencing efforts to maintain a positive outlook.

Interviewees almost entirely narrated negative experiences as only temporary, whether referring to instances of self-disconnection or experiences of living in poor housing conditions. This was particularly the case for Tracy and Jo, graduates with experience of living in houses in multiple occupation as students. The findings here again demonstrate similarities to those of Bouzarovski et al. ${ }^{12}$ in that Jo's interpretation of the standard of housing students deserve or should expect is bound up in wider cultural expectations. Jo relates to a stereotypical image of 'student squalor'12, where poor housing conditions are to be endured by certain households. However, reflecting on her housing experience as a student, Jo does not identify as one of those who deserves to have been living in such conditions. Responding to her situation at the time, Jo revealed that a sense of powerlessness to make changes resulted in her adopting this mechanism of coping. Lastly, another psychological mechanism of coping related to the temporality of participants' narratives. Notably, almost all of the negative experiences discussed were situated in the past. When talking about the present, and the future, interviewees did so with a seemingly genuine sense of self-confidence and positivity. On some occasions, concerted efforts were made to demonstrate that their current home life was characterised more by positive experiences, which were manageable, than by negative experiences. This was noted on a number of occasions where, after disclosing a negative (past) experience, participants ensured they concluded such narratives with a statement illustrating that this 
wasn't a reflection of their current situation: "oh its better, it's better now, it's much better" (Janet).

While this may reflect an accurate representation of the interviewees' current circumstances, it may also offer evidence of a psychological strategy for responding to and managing negative experiences. Arnett ${ }^{49}$ identified that, with regard to their own personal situations, young adults overwhelmingly demonstrate a strong sense of optimism for the future. Given the potential failure among this group to recognise conditions indicative of fuel poverty ${ }^{12}$, it is possible that efforts to maintain a sense of optimism has an influential role in young adults' understanding of their own energy vulnerability.

\section{DISCUSSION AND CONCLUSION}

The main purpose of this research was to build upon a limited understanding of the nature and experiences of fuel poverty among low-income, non-student, young adult households. At present in the UK, this demographic group face significant challenges, not only in relation to fuel poverty, but also in terms of their likelihood to be living with lower than average incomes, in some of the poorest housing, and with significantly higher than average levels of personal debt. ${ }^{50}$ Given the myriad of challenges faced, as well as a recognition that young adult households may not conceive of themselves as living in or at risk of fuel popverty ${ }^{12}$, our focus was deliberately broadened beyond fuel poverty in a narrow sense, to also consider young adults' experiences of moving into and managing the independent home. Despite being small in scale and of an exploratory nature, this approach has been useful in generating a more detailed understanding of the issue among this demographic group, as well as illustrating a number of directions for future research. 
With such a limited body of existing research in this area, it was expected that a number of avenues for further research would be identified. Indeed, any one of the master themes considered in isolation would open up the potential to generate an even greater understanding of the issue as experienced by young adult households. For example, research focused on young adults and housing, more broadly, has recognised that the practices and processes of making home, while seen to be critical, have been somewhat neglected within the field. ${ }^{38}$ Although limited, associations between 'making home' and young adults' experiences of energy-related challenges were revealed by the interviewees; this demonstrates just one possibility for future research, and one which would arguably benefit from a multidisciplinary approach.

Our findings generally supported many of those evidenced by previous research. ${ }^{12} \mathrm{~A}$ range of household conditions indicative of fuel poverty was disclosed by the interviewees, such as self-disconnection of energy supply, energy debts, ill-health, unrelenting challenges associated with damp and mould, and some limited references to a lack of thermal comfort. However, interviewees frequently seemed to reject a sense of vulnerability, situating negative experiences in the past, and talking about their present and future circumstances in a positive way. This raises an important consideration for fuel poverty initiatives targeted towards this demographic group, where the approach used should take steps to reflect the way in which the problem is perceived by those experiencing it. For instance, strategies that aim to empower young adult households, shifting the focus away from vulnerability, may prove to be more effective.

A major limitation of this study, and a potential reason for a lack of references to cold homes or thermal comfort, relates to the time of year in which data collection took place. 
Interviews were conducted during May and June, typically recognised as warmer months. Therefore, at the time of being interviewed, the young adults' concerns regarding colder indoor temperatures may not have been as significant as during other (colder) months throughout the year. It has been noted, however, that fuel poverty does not only concern thermal comfort or the ability to achieve adequate warmth, but also the impacts of domestic energy deprivation with regard to other energy services such as lighting, cooking, cleaning and entertainment. In the discussion of the second master theme, this was illustrated by the interviewees who disclosed four distinct energy threats to comfort that went beyond adequate and affordable warmth. To some extent, this demonstrates a benefit of conducting the research outside of colder months, where individuals are arguably able to reflect on the broader experiences of energy, and consequently their perceptions of energy vulnerability during these times, also.

As well as being restricted in terms of sample size, the analysis is also restricted as a result of the process taken to recruit interviewees. All participants were recruited following contact with the local advice organisation and therefore the analysis only considers the experiences of young adults who have actively sought out help or advice (regarding energy related issues, or otherwise). As such, it is unrealistic to generalise findings to the wider demographic group, meaning it is also difficult to establish how typical such experiences may be for other young adults. Further research could consider alternative sampling and recruitment strategies, particularly where such approaches are able to demonstrate effectiveness in targeting hard to reach groups, such as young adults. ${ }^{51} \mathrm{It}$ is also important to consider the benefits of quantitative and mixed methods approaches, such as the ability to analyse much larger sample sizes and therefore to develop a more complete understanding of the issue among this demographic group. 
The diversity of the sample, despite consisting of only six individuals, emphasised the importance of acknowledging young adults as a heterogeneous group. Interviewees narrated their experiences through various identities, such as that of a parent, a student, a refugee, a spouse, a friend, or a neighbour, among many others. The substantial variations between the interviewees' experiences could be explained in terms of individual differences; however, such findings also reveal critical opportunities to explore key subdemographic groups of young adults. Considering only the diversity of the sample in this research, sub-demographic groups could include: those who have experienced periods of homelessness, lone-parent young adult households, young adults moving from care, nonstudent populations living in predominantly student areas, or those with illnesses or disabilities.

Exploratory in nature, this paper aimed to contribute to a gap in the existing evidence base, presenting a discussion of the findings from a small-scale qualitative study that explored how an under-researched demographic group construct and make sense of their energyrelated experiences, as well as their experiences of energy-related challenges and vulnerabilities. At the centre of this was a goal to ensure that a study of fuel poverty or energy vulnerability among young adult households could remain grounded in the perspectives of young adults themselves, contributing also to the growing body of work that advocates 'bottom up' approaches. As a novel qualitative research approach in the study of fuel poverty, and therefore, one that promotes methodological innovation in the field, IPA has proved to be particularly beneficial in achieving the research aims, as well as revealing a number of key insights regarding just one specific area of focus within the wider evidence base. 


\section{Authors' contribution}

DB designed the study, collected the data and completed the analysis. GS contributed to interpretations of the data, particularly in the later stages of data analysis. DB and GS jointly produced the manuscript and performed revisions. All authors contributed equally in the preparation of this manuscript.

\section{Acknowledgements}

We thank the reviewers for their valuable comments on an earlier version of this paper, which has been strengthened as a result. We would like to thank Salford Citizens Advice for their professional and expert support throughout the completion of the research, as well as for providing the space in which to carry out the interviews.

\section{Declaration of conflicting interests}

The author(s) declared no potential conflicts of interest with respect to the research, authorship, and/or publication of this article.

\section{Funding}

This research was undertaken to fulfil the requirements of a postgraduate research degree that was self-funded; however, we would like to thank The Eaga Charitable Trust for generously awarding a Masters bursary to support its completion.

\section{References:}

1. Department for Energy and Climate Change. Annual Fuel Poverty Statistics Report, https://www.gov.uk/government/statistics/annual-fuel-poverty-statistics-report-2016 (2016, accessed $1^{\text {st }}$ August 2016)

2. Boardman B. Fixing fuel poverty: challenges and solutions. London: Earthscan, 2013. 
3. Middlemiss LK, Gillard R. "How can you live like that?": energy vulnerability and the dynamic experience of fuel poverty in the UK. Report, University of Leeds, UK, 2014. 4. Sherriff G. "I was frightened to put the heating on." Evaluating the Changes4Warmth approach to cold homes and mental health. Report, University of Salford, UK, 2016.

5. Shorrock L, Utley J. Domestic energy fact file 2003, http://projects.bre.co.uk/factfile/BR457prtnew.pdf (2003, accessed $1^{\text {st }}$ March 2016) 6. Buzar S. When homes become prisons: the relational spaces of postsocialist energy poverty. Environment and Planning A 2007; 39(8): 1908-25.

7. Marmot M, Bell R. Fair society, healthy lives. Public health 2012; 126: S4-S10.

8. Liddell C, Guiney C. Living in a cold and damp home: frameworks for understanding impacts on mental well-being. public health 2015; 129(3): 191-199.

9. Office for National Statistics. Nowcasting household income in the UK: financial year ending, https://www.ons.gov.uk/peoplepopulationandcommunity/personalandhouseholdfinances/i ncomeandwealth/bulletins/nowcastinghouseholdincomeintheuk/2015to2016 (2016, accessed $15^{\text {th }}$ May 2016)

10. Citizens Advice. Benefits for people looking for work, https://www.citizensadvice.org.uk/benefits/in-work-or-looking-for-work/benefits-forpeople-looking-for-work/ (accessed $17^{\text {th }}$ May 2016)

11. Ambrose AR. Improving energy efficiency in private rented housing: Why don't landlords act?. Indoor Built Environ 2015; 24(7): 913-24. 
12. Bouzarovski S, Petrova S, Kitching M, Baldwick J. Precarious domesticities: energy vulnerability among urban young adults. Energy justice in a changing climate-Social equity implications of the energy and low carbon relationship. London: Zed Books. 2013.

13. Carlsson-Kanyama A, Lindén AL, Eriksson B. Residential energy behaviour: does generation matter?. International Journal of Consumer Studies 2005; 29(3): 239-53.

14. Lindén AL, Carlsson-Kanyama A, Eriksson B. Efficient and inefficient aspects of residential energy behaviour: What are the policy instruments for change?. Energy policy 2006; 34(14): 1918-27.

15. Middlemiss L, Gillard R. Fuel poverty from the bottom-up: characterising household energy vulnerability through the lived experience of the fuel poor. Energy Res Soc Sci 2015;

6: $146-154$

16. Lusambili AM, Tod AM, Homer C, Abbott J, Cooke J, McDaid KA. Keeping Warm: Social Connectedness and Technology-A Case Study of Rotherham, England 'Technology and Health in the Elderly'. International Journal of Health, Wellness \& Society 2011; 1: 27-42.

17. Harrington BE, Heyman B, Merleau-Ponty N, Stockton H, Ritchie N and Heyman A. Keeping warm and staying well: findings from the qualitative arm of the Warm Homes Project. Health Soc Care Community 2005; 13: 259-267

18. Willig C. Introducing qualitative research in psychology. Buckingham: Open University Press, 2001.

19. Wilson A. A guide to phenomenological research. Nursing Standard 2015; 29(34): 38-43. 20. Smith JA, Flowers P, Larkin M. Interpretative Phenomenological Analysis. London: Sage, 2009. 
21. Smith JA. Reflecting on the development of interpretative phenomenological analysis and its contribution to qualitative research in psychology. Qualitative research in psychology 2004; 1(1): 39-54.

22. Sullivan C, Gibson S, Riley SC. Doing Your Qualitative Psychology Project. London: Sage, 2012.

23. Frost N. Qualitative research methods in psychology: Combining core approaches. Columbus,: McGraw-Hill Education, 2011.

24. National Energy Action. UK Fuel Poverty Monitor 2014 - 2015: key findings \& recommendations of the full report, http://www.nea.org.uk/Resources/NEA/Publications/Fuel\%20Poverty\%20Monitor\%20SUM MARY.pdf (2015, accessed $17^{\text {th }}$ March 2016)

25. Hills J. Getting the measure of fuel poverty: final report of the fuel poverty review. London School of Economics CASE Report 72, London, 2012.

26. Department for Energy and Climate Change. Annual Fuel Poverty Statistics Report, London, Office for National Statistics, 2015, https://www.gov.uk/government/uploads/system/uploads/attachment_data/file/429873/F uel_Poverty_Annual_Report_2015.pdf (2015, accessed 1 ${ }^{\text {st }}$ May 2016)

27. Department for Energy and Climate Change. Understanding the behaviours of households in fuel poverty, https://www.gov.uk/government/uploads/system/uploads/attachment_data/file/332122/u nderstanding_behaviours_households_fuel_poverty_review_of_research_evidence.pdf (2014, accessed $1^{\text {st }}$ April 2016) 
28. Costley C, Elliott GC, Gibbs P. Doing work based research: Approaches to enquiry for insider-researchers. London: Sage, 2010.

29. Ritchie J, Lewis J, Nicholls CM, Ormston R. (Eds.) Qualitative research practice: A guide for social science students and researchers. London: Sage, 2013.

30. Onwuegbuzie AJ, Leech NL. Sampling designs in qualitative research: Making the sampling process more public. The qualitative report 2007; 12(2): 238-54.

31. Sandelowski M. Sample size in qualitative research. Research in nursing \& health 1995; 18(2): 179-83.

32. Ritchie J, Lewis J, Nicholls CM, Ormston R. (Eds.). Qualitative research practice: A guide for social science students and researchers. London: Sage, 2013.

33. Guest G, Bunce A, Johnson L. How many interviews are enough? An experiment with data saturation and variability. Field methods 2006; 18(1): 59-82.

34. Robinson OC. Sampling in interview-based qualitative research: $A$ theoretical and practical guide. Qualitative Research in Psychology 2014; 11(1): 25-41.

35. Bertaux D. Bibliography and Society: The Life History Approach in the Social Sciences. London: Sage, 1981.

36. Pietkiewicz I, Smith JA. A practical guide to using interpretative phenomenological analysis in qualitative research psychology. Psychological Journal 2014; 20(1): 7-14. 37. Larkin $\mathrm{M}$, Watts $\mathrm{S}$, Clifton E. Giving voice and making sense in interpretative phenomenological analysis. Qualitative research in psychology 2006; 3(2): 102-20. 38. Hopkins PE. Young people, place and identity. London: Routledge, 2010. 
39. Perkins $H$, Thorns DC. Place, identity and everyday life in a globalizing world. London: Palgrave Macmillan, 2011.

40. Department for Energy and Climate Change. Cutting the cost of keeping warm: a fuel poverty strategy for England, https://www.gov.uk/government/uploads/system/uploads/attachment_data/file/408644/c utting_the_cost_of_keeping_warm.pdf (2015, accessed on $1^{\text {st }}$ July 2016)

41. Cauvain J, Bouzarovski S. Energy vulnerability in multiple occupancy housing: a problem that policy forgot. People, Place \& Policy Online 2016; 10: 88-106.

42. Hards SK. Status, stigma and energy practices in the home. Local Environment 2013; 18(4): $438-54$

43. Ofgem. Domestic Suppliers' Social Obligations: 2013 annual report, https://www.ofgem.gov.uk/sites/default/files/docs/2014/12/annual_report_2013_final_for _publication.pdf $\left(2014\right.$, accessed $1^{\text {st }}$ May 2016)

44. Vulnerable Consumer Working Group. Guidance Document on Vulnerable Consumers, http://ec.europa.eu/energy/sites/ener/files/documents/20140106_vulnerable_consumer_r eport_0.pdf (2013, accessed $15^{\text {th }}$ January 2017)

45. Olsson CA, Bond L, Burns JM, Vella-Brodrick DA, Sawyer SM. Adolescent resilience: A concept analysis. Journal of adolescence 2003; 26(1): 1-11.

46. Gibbons D, Singler R. Cold comfort: A review of coping strategies employed by households in fuel poverty. London: Centre for Economic and Social Inclusion, 2008.

47. Brunner KM, Spitzer M, Christanell A. Experiencing fuel poverty. Coping strategies of low-income households in Vienna/Austria. Energy Policy 2012; 49: 53-9. 
48. Tod AM, Nelson P, de Chavez AC, Homer C, Powell-Hoyland V, Stocks A. Understanding influences and decisions of households with children with asthma regarding temperature and humidity in the home in winter: a qualitative study. BMJ open 2016; 6(1): 1-14.

49. Arnett JJ. Emerging adulthood: A theory of development from the late teens through the twenties. American psychologist 2000; 55(5): 469.

50. Go Compare Press Office. Generation Debt: new report reveals young people's attitudes to debt, http://www.gocompare.com/press-office/2015/09/generation-debt/ (accessed 11 ${ }^{\text {th }}$ August 2016)

51. Abrams LS. Sampling 'hard to reach' populations in qualitative research: The case of incarcerated youth. Qualitative Social Work 2010; 9(4): 536-50. 